\title{
Representaciones de la ciudad en el teatro áureo. Nota preliminar

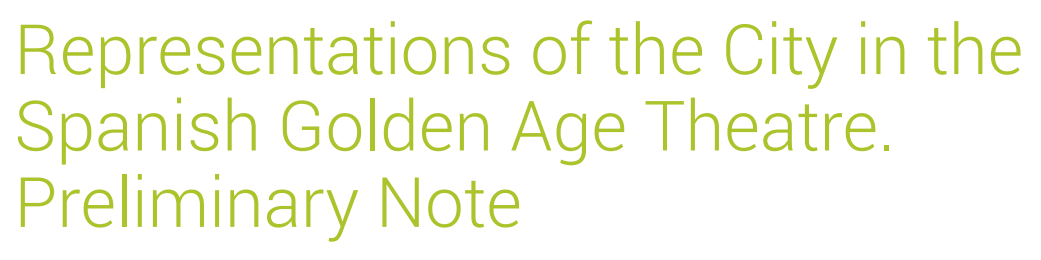

\section{Blanca Oteiza}

http://orcid.org/0000-0003-4175-846X

Universidad de Navarra, GRISO

ESPAÑA

boteiza@unav.es

\section{Karolina Kumor}

Universidad de Varsovia

POLONIA

k.kumor@uw.edu.pl

[Hipogrifo, (issn: 2328-1308), 8.2, 2020, pp. 9-10]

DOl: http://dx.doi.org/10.13035/H.2020.08.02.02

Del 31 de mayo al 1 de junio de 2019 se celebró en Varsovia el IV Simposio Internacional Representaciones de la ciudad en el teatro español: del Siglo de Oro a la actualidad, organizado por el Instituto de Estudios Ibéricos e Iberoamericanos de la Universidad de Varsovia y por el GRISO (Grupo de Investigación Siglo de Oro) de la Universidad de Navarra. El resultado del encuentro se materializó en un primer volumen sobre las manifestaciones urbanas en la actualidad, a cargo de J. Enrique Duarte y Kamil Seruga (eds.), que con el título Representaciones de la ciudad en el teatro español (siglos XX y XXI) fue publicado a principios de este año 2020 (New York, IDEA / IGAS).

Ahora, presentamos una selección de los trabajos leídos sobre el Siglo de Oro (con una contribución anexa sobre la pintura) que ocupa esta sección monográfica de la revista Hipogrifo dedicada a las Representaciones de la ciudad en el teatro áureo.

La ciudad es, sin duda, uno de sus escenarios privilegiados y como tal tiene un lugar significativo en la bibliografía de los últimos años que se ha ocupado en razonar los fundamentos teóricos sobre la construcción de sus espacios escénicos y dramáticos, a los que este monográfico contribuye con el análisis de un corpus que permite confirmar, completar y matizar su tratamiento en unos modelos dramáti- 
cos que irán agotándose con el uso y el tiempo, pero a los que la ciudad sobrevivirá en distintos y nuevos géneros teatrales.

Son once artículos que interpretan la representación de la ciudad en el teatro y pintura áureos en varios tiempos, autores, géneros y perspectivas. Partiendo de 1585, año aproximado de escritura de la tragedia cervantina La Numancia (de la que se ocupan Urszula Aszyk y Pablo de la Fuente de Pablo), se sigue con la obra sacramental y cómica de Lope de Vega (a cargo de J. Enrique Duarte y Eva Gutiérrez Prada) y con sendas comedias de Tirso de Molina, la atribuida El condenado por desconfiado que estudia Isabelle Bouchiba-Fochesato, y Desde Toledo a Madrid analizada por Naïma Lamari, y se continúa más allá de la mitad del XVII con Calderón y otros dramaturgos de su ciclo: en El desdén, con el desdén de Moreto se centra Inmaculada Ruiz Ruiz; Antonio Guijarro-Donadiós se interesa por Abrir el ojo de Rojas Zorrilla; Enrica Cancelliere profundiza en el teatro de Calderón y al entremesista Quiñones de Benavente dedica su trabajo Edimilson Rodrigues. Y la ciudad también es considerada desde la correspondencia entre la pintura y la literatura por Jesús Ángel Sánchez Rivera.

Textos que ofrecen un tratamiento de la ciudad desde múltiples perspectivas: ciudades reales o míticas (Numancia, Madrid, Toledo, Valencia, Barcelona, Jerusalén...) por cuyas plazas y calles transitan sus habitantes y personajes, o en cuyos edificios y dependencias viven o malviven (el estrado, la cárcel). Pero el lector advertirá también cómo estas ciudades adquieren en muchas ocasiones importantes funciones simbólicas en las estrategias y destinos particulares o colectivos de los personajes, trascendiendo de la ciudad terrenal a la ciudad celestial, en un paseo que deleita y aprovecha. 